tuberculosis in health care workers in central France.

I studied cases of tuberculosis in hospital employees between 1984 and 1992. Sixty two cases of occupationally acquired tuberculosis occurred during this period. In all cases the employees had had BCG vaccination, but in 41 cases the tuberculosis occurred more than 15 years after the vaccination. The World Health Organisation and many authors consider that BCG vaccination gives about $80 \%$ protection, but only for 15 years. ${ }^{2}$ Thus in these 41 cases the protection offered by BCG vaccination may have disappeared. Health care workers should have a tuberculin skin test at least every two years. A further BCG injection should be given if the result of the test is negative. In 44 cases in this study tuberculosis was detected by a routine chest $x$ ray examination. Chest $x$ ray screening, though more costly, is more effective than skin testing.

As the number of patients admitted to hospital with HIV infection and tuberculosis increases, the risk of nosocomial transmission to staff may rise, and new thought must be given to prevention.

JACQUES GERMANAUD

Department of Preventive Medicine,

Hospital of Orleans,

45032 Orleans,

France

1 Citron KM. BCG vaccination against tuberculosis: international perspectives. $B M 7$ 1993;306:222-3. (23 January.)

2 Clemens JD, Chuong JJH, Feinstein AR. The BCG controversy.

A methodological and statistical reappraisal. JAMA 1983;249: 2362-9.

\section{Toxic shock syndrome after minor surgery}

EdrToR,-We believe that there are two other important lessons to be learnt from A R J Bosley and colleagues' lesson of the week on toxic shock syndrome after minor dermatological surgery.' Septic shock is defined by its characteristic haemodynamic profile, ${ }^{2}$ which is independent of the infective organism. ${ }^{3-5}$ Suspicion of this diagnosis should, in our view, result in the patient being transferred to the intensive care unit immediately.

The initial management is supportive, requiring invasive haemodynamic monitoring with arterial, central venous, and pulmonary artery flotation catheters in most cases. Vigorous resuscitation with intravenous fluid and support with inotropes and vasoconstrictors should be started without delay to optimise oxygen delivery and transport. Specific treatment, currently antibiotics and surgical debridement, guided by investigations to localise and identify the infective organism is equally important. Despite the above measures septic shock, regardless of aetiology, continues to have a mortality of $60-90 \% 0^{.8-8}$ In our opinion, only by early recognition and aggressive intervention can a patient's chances of survival be increased.

Secondly, transport of such critically ill patients to regional referral centres should be considered and discussed early in the clinical course. Complications during transport are, in our experience, common and life threatening and thus demand adequate equipment and appropriate numbers of experienced staff.

MARK J D GRIFFITHS

DAVID G SINCLAIR

Adult Intensive Care Unit,

Royal Brompton National Heart and Lung Hospital,

London SW3 6NP

1 Bosley ARJ, Bluett NH, Sowden G. Toxic shock syndrome after elective minor dermatological surgery. $B M M^{\prime}$ 1993;306:386-7. (6 February.)

2 Bone RC. Sepsis, the sepsis syndrome, multi-organ failure: a plea for comparable definitions. Ann Intern Med 1991;114:332-3.

3 Bone RC, Fisher CH, Clemmer TP, Stotman GH, Metz GA, Balk RA. A controlled clinical trial of high dose methylprednisolone in the treatment of severe sepsis and septic shock. N Engl f Med 1987;317:653-8.
4 Ispahani P, Person NH, Greenwood D. An analysis of community and hospital acquired bacteraemia in a large teaching hospital in the UK. Qf Med 1987;241:427-40.

5 Calandra T, Glauser TP, Schellekens J, Verhoef J, Swiss-Dutch J5 Immunoglobulin Study Group. Treatment of Gram negative septic shock with human IgG antibody to $E$ coli J5: a prospective double-blind randomised study. I Infect Dis 1988;158:312-9.

6 Young LS, Martin WJ, Meyer RD, Weinstein RJ, Anderson ET Gram negative rod bacteremia: microbiologic, immunologic and therapeutic considerations. Ann Intern Med 1977;86: 456-71

7 Dupont HL, Spink WW. Infections due to Gram negative organisms: an analysis of 860 patients with bacteraemia at the University of Minnesota Medical Center 1958-66. Medicine 1969;48:307-32.

8 Perlino CA, Rimland D. Alcoholism, leucopenia and pneumococcal sepsis. Am Rev Respir Dis 1985;132:757-60.

EDrroR,-In their comments on the treatment of toxic shock syndrome A R J Bosley and colleagues do not mention the use of blood products containing human immunoglobulin.' In toxic shock syndrome in burnt children specific treatment entails the use of intravenous human immunoglobulin, either as a concentrate or in the form of fresh frozen plasma or whole blood. ${ }^{2}$ Appropriate intravenous antibiotic treatment should also be given, but this alone will not neutralise the toxin that has already been produced and absorbed into the circulation. Circulatory support with plasma expanders is usually essential and may prevent the onset of shock.

Specific treatment with immunoglobulin early in the course of the illness is likely to be equally appropriate in toxic shock syndrome occurring in association with surgical procedures or with other conditions and should perhaps be recommended. Early diagnosis of the syndrome, though difficult, is important. Use of the term staphylococcal toxaemia might emphasise the need to treat this condition specifically and before the development of shock, which has a far higher associated mortality. ${ }^{3}$ Bosley and colleagues' suggestion that there is a need for the condition to become notifiable should be supported. R M R MCALLISTER

Restoration of Appearance and Function Trust,

Mount Vernon Hospital,

Northwood,

Middlesex HA6 2RN

1 Bosley ARJ, Bluett NH, Sowden G. Toxic shock syndrome after elective minor dermatological surgery. BMF 1993;306:386-7. (6 February.)

2 Frame JD, Eve MD, Hackett MEJ. The toxic shock syndrome in burned children. Burn 1985;11:234-41.

3 McAllister RMR, Mercer NSG, Morgan BDG, Sanders R. Early diagnosis of staphylococcal toxaemia in burned children. Bur 1993;19:22-5.

\section{Selective decontamination of the gut}

EdrToR,-Simon W Atkinson and David J Bihari's views on selective decontamination of the gut and related issues are unlikely to improve accepted standards in intensive care units.' Most publications on the use of selective decontamination of the gut have reported a reduction in rates of infection, ${ }^{2}$ but few have resulted in improved survival. This discrepancy could be explained by the fact that these studies were of poor design, with insufficient power to detect changes in mortality. Another important consideration might be that infection is not important in determining mortality in critically ill patients and that the type of infection seen in these patients (that is, nosocomial infections) is the consequence of their illness rather than the cause of it.

In many large series of critically ill patients sepsis has been found to be a major determinant of mortality. The term "sepsis" is misleading. Though all doctors recognise the associated clinical signs of fever and hyperdynamic circulation, few people appreciate that although infection is the commonest cause of sepsis, infection is not necessary to maintain this clinical state; most patients with multiple organ failure die with advanced signs of sepsis but no bacteriological evidence of infection. The inflammatory state is maintained by interactions between the vascular endothelium and cells of the immune system, one of the common final pathways being activation of arachidonic acid metabolism. To avoid the connotations of infection it would be better, therefore, to abandon the term sepsis and use the recently introduced "systemic inflammation." ${ }^{3}$

Both Marshall and Sweeneyt and our groups have shown that systemic inflammation may be more important than infection in determining mortality. We have also shown that selective decontamination of the gut has antiseptic (antiinflammatory) properties, which may be additional to its anti-infective (antibacterial) effect.

Other measures to prevent bacterial overgrowth such as avoidance of $\mathrm{H}_{2}$ antagonists are likewise unlikely to have any effect on mortality, though Atkinson and Bihari support these measures. It is true that medical staff neglect their hand hygiene, but intensive care nursing staff, who have most contact with the patients, maintain high standards. Other recommendations such as regular change of vascular access have no proved value, and we remain too ignorant on nutritional issues to give clear guidelines on this subject-though at least we agree that nutrition is a good thing.

Selective decontamination of the gut clearly does what it set out to do (reduce infection rates). That some of its actions remain unknown is a stimulus to further research, and with sufficient collaboration between intensive care units definitive work could easily be performed. RG WILKES

Royal Liverpool University Hospital, S M MOSTAFA

Liverpool L7 8XP

1 Atkinson SW, Bihari DJ. Selective decontamination of the gut. $B M \mathcal{A}$ 1993;306:286-7. (30 January.)

2 Van Saene HKF, Stoutenbeek CP, Stoller JK. Selective decontamination of the digestive tract in the intensive care unit: current status and future prospects. Crit Care Med 1992;20 691-705.

3 Definitions for sepsis and organ failure and guidelines for the use of innovative therapies in sepsis. American College of Chest Physicians/Society of Critical Care Medicine Consensus Conference. Crit Care Med 1992;20:864-74.

4 Marshall JC, Sweeney D. Microbial infection and the septic response in critical surgical illness. Sepsis, not infection, response in critical surgical illness. Sepsis,
determines outcome. Arch Surg 1990;125:17-25.

5 McClelland P, Murray A, Yaqoob M, Van Saene HKF, Bone JM, Mostafa SM. Prevention of bacterial infection and sepsis in acute severe pancreatitis. Ann Roy Coll Surg Engl 1992;74: 329-34.

\section{Risks to surgeons and patients from HIV and hepatitis}

EDrTor,-In addition to the risks to health care staff and patients from HIV and hepatitis B outlined by the Joint Working Party of the Hospital Infection Society and the Surgical Infection Study Group,' during "invasive procedures" there is also a risk of transmission from health care staff to patients. ${ }^{2}$

The joint working party's paper correctly highlights the problem that one possible reason for nonresponse to hepatitis $\mathrm{B}$ vaccines is a pre-existing hepatitis B carrier status and suggests that nonresponders should be tested for hepatitis $B$ antigen to identify infectious carriers and advise them against carrying out invasive procedures.

During a 12 month period our laboratory investigated 10871 people who had had a course of hepatitis $B$ vaccine. Those who failed to respond to vaccine (concentration of antibodies to hepatitis $B$ surface antigen $<10 \mathrm{IU} / 1 ; 14 \%$ of those vaccinated) were first tested for antibodies to hepatitis B core antigen, a marker of past or current infection with 